\title{
Inner Restlessness
}

National Cancer Institute

\section{Source}

National Cancer Institute. Inner Restlessness. NCI Thesaurus. Code C117167.

A feeling of unrest and/or an inability to feel calm or relaxed. 